\title{
Gambaran Kepuasan Kerja Perawat di Ruang Rawat Inap RSUD Wangaya Denpasar
}

\author{
Ni Made Nopita Wati ${ }^{1}$, I Gede Juanamasta ${ }^{2}$, Ni Luh Suartini ${ }^{3}$ \\ STIKes Wira Medika Bali, Jl Kecak No.9A, Denpasar, Bali ${ }^{1}$ \\ STIKes Wira Medika Bali, Jl Kecak No.9A, Denpasar, Bali ${ }^{2}$ \\ RSUD Wangaya Denpasar, J1. Kartini No.133, Denpasar, Bali \\ E-mail : ners.pita@gmail.com \\ Doi: https://doi.org/10.30787/gaster.v18i2.418
}

Received: May 2019| Revised: July 2019| Accepted: September 2019

\begin{abstract}
ABSTRAK
Pendahuluan: Kepuasan kerja terhadap kinerja karyawan dan staf di rumah sakit merupakan salah satu faktor yang mempengaruhi kualitas pelayanan kesehatan. Ketidakpuasan kerja terhadap suatu pekerjaan akan berdampak pada menurunnya motivasi kerja, menurunnya loyalitas karyawan serta mengakibatkan tingginya tingkat perputaran karyawan atau turnover. Penelitian ini bertujuan untuk mengetahui gambaran kepuasan kerja perawat di Ruang Rawat Inap RSUD Wangaya. Metode: Penelitian ini menggunakan metode Deskriftif Kuantitatif dengan jumlah populasi 165 perawat dan jumlah sampel sebanyak 130 responden dengan teknik pengambilan sampel purpossive sampling. Adapun instrumen penelitian yang digunakan yaitu kuisioner kepuasan kerja. Hasil: Hasil peneilitian ini menunjukkan karakteristik perawat di ruang rawat inap RSUD Wangaya Kota Denpasar, yaitu yang mendominasi berjenis kelamin perempuan sebesar $74,6 \%$, dengan paling banyak dalam rentang umur antara 20-30 tahun sebesar 62,3\%, perawat paling banyak berlatar belakang pendidikan DIII Keperawatan sebesar 55,4\%, perawat dengan status kawin paling banyak sebesar 68,5\% dan perawat paling banyak memiliki masa kerja antara 1-5 tahun sebesar 60,1\% dan sebanyak 94,6\% perawat menyatakan cukup puas bekerja di RSUD Wangaya. Kesimpulan: penelitian ini menunjukkan hasil bahwa sebagian besar perawat merasa puas dengan pekerjaannya sebagai perawat di Ruang Rawat Inap RSUD Wangaya Denpasar. Hasil penelitian ini juga menunjukkan item kuisioner "Pemberian insentif tambahan atas suatu prestasi atau kerja ekstra" paling banyak responden yang menyatakan tidak puas yaitu 76 responden (58,5\%). Berdasarkan hasil penelitian dapat disarankan agar RSUD Wangaya hendaknya tetap melaksanakan survei kepuasan kerja perawat, meningkatkan transparansi sistem keuangan dan memberikan insentif yang adil sesuai kebijakan agar meningkatkan kepuasan pegawai.
\end{abstract}

Kata kunci : kepuasan kerja, perawat, rumah sakit

\section{ABSTRACT}

Introduction: Job satisfaction on the performance of employees and staff at the hospital is one of the factors that affect the quality of health services. Job dissatisfaction will have an impact on decreasing work motivation, decreasing employee loyalty and resulting in high employee turnover. 
The research aims to describe the job satisfaction of nurses in the Inpatient Room at Wangaya Hospital. Method: This study uses descriptive quantitative method with a population of 165 nurses and a total sample of 130 respondents with purposive sampling technique. The instrument of this research used the job satisfaction questionnaire. Results: The results of this study show the characteristics of nurses in the inpatient ward of Wangaya Hospital, Denpasar City, which dominates female sexes at $74.6 \%$, with the most in the age range between 20 -30 years at $62.3 \%$, nurses with the most backgrounds behind the education of Diploma Nursing was 55.4\%, nurses with the most married status were $68.5 \%$ and nurses had the most working years between 1-5 years were $60.1 \%$ and as many as $94.6 \%$ nurses stated they were quite satisfied working in Wangaya Hospital. Conclusion: this study shows the results that most nurses feel satisfied with their work as nurses in the Inpatient Room of Wangaya Hospital Denpasar. The results of this study also show the item questionnaire "The provision of additional incentives for an achievement or extra work" at most respondents who expressed dissatisfaction that is 76 respondents (58.5\%). Based on the results of the study it can be suggested that the Wangaya Hospital should continue to carry out a nurse job satisfaction survey, improve financial system transparency and provide fair incentives according to policies in order to improve employee satisfaction.

Keywords: level of job satisfaction, nurse, hospital

\section{PENDAHULUAN}

Keberhasilan rumah sakit sangat dipengaruhi oleh kinerja karyawannya. Kinerja karyawan dipengaruhi oleh banyak faktor salah satunya adalah faktor kepuasan kerja. Kepuasan kerja dalam pekerjaan adalah kepuasan kerja yang dinikmati dalam pekerjaan dengan memperoleh pujian hasil kerja, penempatan, perlakuan, peralatan dan suasana lingkungan kerja yang baik sedangkan kepuasan kerja diluar pekerjaan adalah kepuasan kerja yang dinikmati diluar pekerjaan dengan besarnya balas jasa yang akan diterima dari hasil kerjanya, agar dia dapat membeli kebutuhannya (Sukmawati, 2016).
Perawat merupakan salah satu sumber daya manusia dirumah sakit yang paling sering berinteraksi dengan pasien dan memiliki jumlah sumber daya yang paling banyak dalam organisasi rumah sakit. Selain itu perawat memiliki shift kerja yang paling tinggi di rumah sakit. Kepuasan kerja perawat menjadi salah satu faktor yang mempengaruhi produktifitas kerja perawat. Perawat harus memiliki dan menjaga kepuasan kerjanya pada sisi positif. Perawat yang memiliki kepuasan kerja positif akan melakukan pekerjaannya dengan lebih baik dan menghasilkan pelayanan yang bermutu.

$$
\text { Ketidakpuasan kerja terhadap }
$$
suatu pekerjaan akan berdampak pada 
menurunnya motivasi kerja, menurunnya loyalitas karyawan serta mengakibatkan tingginya tingkat perputaran karyawan atau turnover, kemangkiran karyawan, dan tindakan-tindakan negatif vital personalia (Mangkunegara, 2010). Seorang perawat yang merasa tidak puas dalam melakukan pekerjaannya akan sering mangkir dalam bekerja. Tingkat kehadiran ini dapat menyebabkan beban kerja perawat yang lain meningkat. Beban kerja yang berat dapat menyebabkan hasil kerja perawat tersebut menjadi tidak maksimal, sehingga dapat mempengaruhi kinerja organisasi (Nursalam, 2013). Penelitian ini bertujuan untuk mengetahui gambaran kepuasan kerja perawat di Ruang Rawat Inap RSUD Wangaya.

\section{METODE DAN BAHAN}

Penelitian ini merupakan penelitian diskriptif dengan menggunakan pendekatan pengumpulan data untuk melihat gambaran tingkat kepuasan kerja perawat di ruang rawat inap RSUD Wangaya Denpasar.

Populasi dalam penelitian ini adalah yaitu seluruh perawat di Ruang Rawat Inap RSUD Wangaya Denpasar yang berjumlah 165 orang. Sampel dalam penelitian ini berjumlah 130 orang yang dipilih dengan dengan cara purpossive sampling. Kriteria sampel dalam penelitian ini adalah sebagai berikut :
1. Kriteria inklusi : Perawat yang bersedia menjadi responden dengan masa kerja minimal 1 tahun.

2. Kriteria eklusi : Perawat yang sedang cuti, ijin, sakit dan tugas belajar selama penelitian berlangsung.

Responden yang sesuai dengan kriteria inklusi dan eksklusi diberi penjelasan mengenai penelitian, kemudian menandatangani informed consent dan mengisi lembar kuesioner.

Penelitian ini berlangsung di RSUD Wangaya pada bulan September-Oktober 2018. Instrumen dalam penelitian ini adalah kuesioner kepuasan kerja yang terdiri dari 20 item pertanyaan menggunakan skala likert.

\section{HASIL DAN PEMBAHASAN}

Tabel 1. Tingkat kepuasan kerja berdasarkan jenis kelamin

\begin{tabular}{cccc}
\hline $\begin{array}{c}\text { Jenis } \\
\text { Kelamin }\end{array}$ & \multicolumn{3}{c}{ Kepuasan Kerja } \\
\hline & Kurang & Cukup & Baik \\
\hline Laki-laki & $0(0 \%)$ & $33(28,9 \%)$ & $0(0 \%)$ \\
Perempuan & $5(3,8 \% 0$ & $90(69,2)$ & $2(1,5 \%)$ \\
Total & $5(3,8 \% 0$ & $123(98,1)$ & $2(1,5 \%)$ \\
\hline
\end{tabular}

Berdasarkan Tabel 1 dapat diketahui bahwa responden paling banyak berjenis kelamin perempuan dengan tingkat kepuasan cukup sebanyak 90 orang (69,2\%). Hasil 
penelitian ini sejalan dengan hasil penelitian Argapati (2013) tentang "Gambaran Kepuasan Kerja Perawat Rawat Inap Rumah Sakit Stella Maris Makassar”, dimana hasil penelitian menunjukkan bahwa distribusi responden paling banyak berjenis kelamin perempuan yang menyatakan kepuasan kerja 75 orang $(62,5 \%)$ dari total 130 responden. Menurut sejarahnya, keperawatan muncul dari peran perspektif perempuan dalam suatu keluarga, maka dianggap wajar bila perawat perempuan lebih banyak dari laki-laki (Rolinson, 2008).

Tabel 2. Tingkat kepuasan kerja berdasarkan status perkawinan

\begin{tabular}{lccc}
\hline $\begin{array}{l}\text { Status } \\
\text { Perkawinan }\end{array}$ & \multicolumn{3}{c}{ Kepuasan Kerja } \\
\hline & Kurang & Cukup & Baik \\
\hline Belum kawin & $2(1,5 \%)$ & $39(28,9 \%)$ & $0(0 \%)$ \\
Kawin & $3(2,3 \% 0$ & $84(69,2)$ & $2(1,5 \%)$ \\
Total & $5(3,8 \% 0$ & $123(98,1)$ & $2(1,5 \%)$ \\
\hline
\end{tabular}

Berdasarkan tabel 2 dapat diketahui bahwa responden paling banyak berstatus kawin dengan tingkat kepuasan cukup yaitu sebanyak 84 orang $(69,2 \%)$. Hasil penelitian ini sejalan dengan penelitian Robbin (2008), yang menyatakan bahwa karyawan yang menikah lebih rendah tingkat keabsenannya, mempunyai tingkat pengunduran diri yang lebih rendah dan lebih puas dengan pekerjaanya dibandingkan dengan yang tidak menikah.

Tabel 3. Tingkat kepuasan kerja berdasarkan umur

\begin{tabular}{cccc}
\hline Umur & \multicolumn{3}{c}{ Kepuasan Kerja } \\
\hline & Kurang & Cukup & Baik \\
\hline 20-30 tahun & $5(3,8 \%)$ & $76(58,4 \%)$ & $0(0 \%)$ \\
$31-40$ tahun & $0(0 \%)$ & $43(33,0 \%)$ & $1(0,7 \%)$ \\
$>40$ tahun & $0(0 \%)$ & $4(3,0 \%)$ & $1(0,7 \%)$ \\
Total & $5(3,8 \%)$ & $123(94,4 \%)$ & $2(1,5 \%)$ \\
\hline
\end{tabular}

Berdasarkan tabel 3 dapat diketahui bahwa responden paling banyak berusia 2030 tahun dengan tingkat kepuasan cukup yaitu sebanyak 76 orang $(58,4 \%)$. Hasil penelitian ini sejalan dengan penelitian Argapati (2013 terdapat 92 responden (70,8\%) yang berada pada rentang umur 20 29 tahun. Menurut teori Siagian(2009) yang menyatakan bahwa umur mempunyai ikatan yang erat dengan berbagai segi kehidupan organisasional. Umur berkaitan erat dengan tingkat kedewasaan atau maturitas perawat. Kedewasaan adalah tingkat kemampuan teknis dalam melaksanakan tugas-tugas maupun kedewasaan psikologis menurut Siagian (2013) semakin lanjut usia seseorang semakin meningkat pula kedewasaan teknisnya, demikian pula psikologisnya, serta menunjukkan kematangan jiwa. Usia semakin meningkat akan meningkatkan pula 
kebijaksanaan kemampuan seseorang dalam pengambilan keputusan, berfikir rasional, kinerja akan meningkat dan kepuasan kerja tercapai.

Tabel 4. Tingkat kepuasan kerja berdasarkan tingkat pendidikanya

\begin{tabular}{cccc}
\hline $\begin{array}{c}\text { Tingkat } \\
\text { Pendidikan }\end{array}$ & \multicolumn{3}{c}{ Kepuasan Kerja } \\
\hline & Kurang & Cukup & Baik \\
\hline $\begin{array}{c}\text { D III } \\
\text { Keperawatan } \\
\text { D IV }\end{array}$ & $0(3,8 \%)$ & $67(58,4 \%)$ & $0(0 \%)$ \\
Keperawatan & $17(33,0 \%)$ & $0(0,7 \%)$ \\
S1 & $0(0 \%)$ & $39(3,0 \%)$ & $2(\%)$ \\
Keperawatan & & & \\
Total & $5(3,8 \%)$ & $123(94,4 \%)$ & $2(1,5 \%)$ \\
\hline
\end{tabular}

Berdasarkan tabel 4 dapat diketahui bahwa responden paling banyak berpendidikan DIII Keperawatan dengan tingkat kepuasan cukup yaitu sebanyak 67 orang $(58,4 \%)$. Hasil penelitian ini sejalan dengan penelitian Argapati (2013) yang mendapatkan responden paling banyak dengan pendidikan DIII Keperawatan sebanyak 109 responden $(83,8 \%)$. Berdasarkan teori keadilan Adams dalam Hasibuan (2013), kepuasan akan tercipta jika terdapat keadilan, baik terhadap pendidikan yang tinggi maupun rendah sehingga sudah sewajarnya apabila semakin tinggi pendidikan karyawan semakin tinggi kepuasan kerjanya, begitu pula dengan yang berpendidikan rendah akan memiliki kepuasan kerja yang tinggi apabila mendapatkan keadilan. Apabila dirasa tidak adil, maka akan timbul ketidakpuasan kerja pada karyawan.

Tabel 5. Tingkat kepuasan kerja berdasarkan masa kerja.

\begin{tabular}{cccc}
\hline Masa Kerja & \multicolumn{3}{c}{ Kepuasan Kerja } \\
\hline & Kurang & Cukup & Baik \\
\hline 1-5 Tahun & $5(3,8 \%)$ & $64(58,4 \%)$ & $0(0 \%)$ \\
5-10 Tahun & $0(0 \%)$ & $43(33,0 \%)$ & $0(0,7 \%)$ \\
$>$ 10 Tahun & $0(0 \%)$ & $16(3,0 \%)$ & $2(\%)$ \\
Total & $5(3,8 \%)$ & $123(94,4 \%)$ & $2(1,5 \%)$ \\
\hline
\end{tabular}

Berdasarkan tabel 5 dapat diketahui bahwa responden paling banyak memiliki masa kerja 1-5 tahun dengan kepuasan kerja cukup yaitu sebanyak 64 orang $(58,4 \%)$. Dari segi ketrampilan perawat yang masa kerjanya lebih lama akan semakin trampil dalam pekerjaannya karena makin sering tindakan keperawatan dilakukan dan bertambahnya pengalaman dalam menangani kondisi sulit pada saat melakukan tindakan tersebut, selain itu ada tuntutan dari tim medis yang menginginkan bahwa perawat harus bisa mengikuti perkembangan zaman oleh karena itu kemampuan dalam ketrampilan harus terus dikembangkan dan dilatihkan kepada perawat melalui pendidikan dan pelatihan yang berkesinambungan, menurut peneliti bila lama kerja kurang diperhatikan berkaitan 
dengan harapan perawat untuk mencapai karir yang lebih tinggi maka akan menurunkan kepuasan kerja. Sehingga perlu dikembangkan penetapan jenjang karir untuk perawat klinik yang dapat mengadopsi keahlian ketrampilan klinik serta penghargaan yang sesuai.

Hasil penelitian menunjukkan, bahwa sebanyak 123 perawat $(94,6 \%)$ menyatakan pada kategori cukup dengan kepuasannya bekerja di RSUD Wangaya. Hasibuan (2013) menjelaskan bahwa kepuasan kerja (Job satisfaction) karyawan harus diciptakan dengan sebaik-baiknya untuk meningkatkan moral kerja, dedikasi, kecintaan, dan kedisiplinan karyawan. Item yang dipilih responden dengan kategori puas sebanyak 87 perawat $(66,9 \%)$ adalah item pernyataan No. 12, yaitu tentang "Sikap teman-teman kerja terhadap Anda". Hal ini menunjukkan adanya kerja sama yang baik antar perawat sehingga responden menyatakan kepuasan saat bekerja di RSUD Wangaya.

Hasil penelitian juga menunjukkan bahwa hasil bahwa item kuisioner No. 4 tentang "Pemberian insentif tambahan atas suatu prestasi atau kerja ekstra" paling banyak responden yang menyatakan tidak puas yaitu sebanyak 76 responden (58,5\%). Berdasarkan data tersebut RSUD Wangaya sebaiknya meningkatkan transfaransi sistem manajemen keuanga dan jika mampu memberikan insentif yang adil sesuai kebijakan dan kesepakatan agar terjadi peningkatan kinerja dan kepuasan pegawai.

\section{SIMPULAN DAN SARAN}

Berdasarkan hasil penelitian dapat disimpulkan bahwa sebagian besar responden berjenis kelamin perempuan dengan tingkat kepuasan cukup sebanyak 90 orang $(69,2 \%)$, sebagian besar responden berstatus kawin dengan tingkat kepuasan cukup yaitu sebanyak 84 orang $(69,2 \%)$, sebagian besar responden berusia 20-30 tahun dengan tingkat kepuasan cukup yaitu sebanyak 76 orang $(58,4 \%)$, sebagian besar responden berpendidikan DIII Keperawatan dengan tingkat kepuasan cukup yaitu sebanyak 67 orang $(58,4 \%)$ dan memiliki masa kerja 1-5 tahun dengan kepuasan kerja cukup yaitu sebanyak 64 orang $(58,4 \%)$.

Pihak RS sebaiknya meningkatkan transparansi sistem manajemen keuangan dan jika mampu memberikan insentif yang adil sesuai kebijakan dan kesepakatan agar terjadi peningkatan kinerja dan kepuasan pegawai. 
Bagi peneliti selanjutnya, diharapkan responden dalam menjawab kuisioner dapat mengembangkan penelitian kepuasan sehingga meminimalisir pengaruh pemberian kerja perawat dengan memasang target waktu yang berbeda pada setiap responden waktu yang sama untuk masing-masing

\section{DAFTAR PUSTAKA}

Argapati, A. K. 2013. Gambaran Kepuasan Kerja Perawat Rawat Inap Rumah Sakit Stella Maris Makassar. (online). Available at : http://repository.unhas.ac.id/bitstream/ handle/123456789/8616/JURNAL\%20ANDI\%20KINARKAS\%20ARGAPATI\%20 \%28K11109256\%29.pdf?sequence=1. Diakses tanggal 6 Agustus 2018

Darsono \& Siswandoko, Tjatjuk. 2011. Sumber Daya Manusia Abad 21.Nusantara Consulting: Jakarta.

Efi, Safitri. 2013. Faktor Faktor yang Mempengaruhi Kepuasan Kerja di Ruang Rawat Inap RS Haji Jakarta Tahun 2013. (online). Available at : http://lib.ui.ac.id/naskahringkas/201509/S-Evi\%20Safitri. Tanggal 10 September 2018

Eman, Sido. 2008. Analisis Hubungan Persepsi Karyawan Terhadap Pelaksanaan TQM dengan Kepuasan Umum dan Kepuasan Kerja Karyawan di RSUD Ambarawa. Tesis FKM Universitas Diponegoro. Tidak dipublikasikan.

Hasibuan. 2013. Manajemen Sumber Daya Manusia (Edisi Revisi) Cetakan Ketujuh Belas. Jakarta: PT BumiAksara.

Hilda dan Alimin. 2014. Hubungan Gaya Kepemimpinan Budaya Organisasi dan Imbalan dengan Kepuasan Kerja dan Kinerja Perawat Pelaksana. Jurnal Sains dan Teknologi Ilmu Kesehatan Vol.4.No.2,April 2014 Universitas Hasanuddin,Makasar.

Kartika Yarnitadrayanti. 2012. Hubungan Kepuasan Kerja Dengan Kinerja Perawat Di Ruang Rawat Inap Rumah Sakit Umum Daerah Kabupaten Bekasi. (online). Diakses dari : http:// journal.unpad.ac.id/index.php/ejournal/article/viewFile/753/799. Tanggal 20 Agustus 2018 
ISSN 1858-3385, E-ISSN 2549-7006

GASTER Vol. 18 No. 2, Agustus 2020

Kusmawati. Roslina. (2004). Gambaran Kepuasan Kerja Perawat di Unit Rawat Inap RS. MH Thamrin Internasional Salemba Jakarta. Tesis Program Magister FKM UI. Jakarta.

Mangkunegara. 2010. Manajemen Sumber Daya Manusia Perusahaan. Bandung : PT Remaja Rosda Karya

Notoatmodjo. 2012. Metodologi Penelitian Kesehatan. Jakarta: Rineka Cipta

Nursalam. 2008. Konsep dan Penerapan Metodologi penelitian Ilmu Keperawatan Pedoman

Skripsi, Tesis dan Instrumen Penelitian Keperawatan. Jakarta: Salemba Medika . 2013. Metodelogi Penelitian Ilmu Keperawatan, Pendekatan Praktis. Jakarta: Salemba Medika 2015. Konsep dan Penerapan Metodelogi Penelitian Ilmu Keperawatan, Pedoman Penyusunan Skripsi, Tesis dan Instrumen Penelitian Keperawatan. Jakarta: Salemba Medika

Peraturan Menteri Kesehatan Republik Indonesia Nomor 56 Tahun 2014 tentang Klasifikasi dan Perizinan Rumah Sakit

Prestawan, Anang. 2010. Hubungan Antara Kepuasan Kerja Dan Disiplin KerjaDengan Produktivitas Kerja Karyawan Asuransi Jiwa Bersama Bumiputera Surakarta. Surakarta; Universitas Sebelas Maret Surakarta. (online). Available at : https://digilib.uns.ac.id/ dokumen/detail/13231/. Diakses tanggal 20 Agustus 2018

Sastroasmoro, S. dan Ismail, S. 2011. Dasar-dasar Metodologi Penelitian Klinis. (4th ed.) Jakarta: Sagung Seto

Siagian. 2009. Kiat Meningkatkan Produktivitas Kerja. Jakarta : Rineka Cipta 2013, Manajemen Sumber Daya Manusia. Jakarta : Bumi aksara

Sinambela, Lijan Poltan. 2012. "Kinerja Pegawai Teori Pengukuran dan Implementasi”. Penerbit Graha Ilmu: Yogyakarta.

Sukmawati, D. E.. 2016. Pengaruh Penilaian Kinerja dan Motivasi Kerja terhadap Kepuasan Kerja Karyawan di Instalasi Rawat Jalan Rumah Sakit Umum Daerah Al Ihsan di 
Kabupaten Bandung. (online). Available at : http://repository.unpas.ac.id/12450/3/ BAB\%20I.pdf. Diakses tanggal 4 Agustus 2018

Sukmawati, D. E.. 2016. Pengaruh Penilaian Kinerja dan Motivasi Kerja terhadap Kepuasan Kerja Karyawan di Instalasi Rawat Jalan Rumah Sakit Umum Daerah Al Ihsan di Kabupaten Bandung. (online). Available at : http://repository.unpas.ac.id/12450/3/ BAB\%20I.pdf. Diakses tanggal 4 Agustus 2018.php/ejournal/article/viewFile/753/799. Diakses tanggal 6 Agustus 2018. 